\title{
THE PREDICTING FACTORS FOR CHRONIC KIDNEY DISEASE AMONG HIGH RISK POPULATION IN LOWER NORTHERN, THAILAND
}

\author{
Primprapha Konkaew ${ }^{1}$ and Pattama Suphunnakul ${ }^{1}$ \\ ${ }^{1}$ Faculty of Public Health, Naresuan University, Phitsanulok, 65000, Thailand \\ Corresponding author: Primprapha Konkaew \\ Email: primppk@hotmail.com
}

\begin{abstract}
This research aimed to explore the factors predicting chronic kidney disease (CKD) in the high-risk population. $A$ cross-sectional study had been conducted in the high-risk populations investigated with and without CKD were the participants. A total of 1,463 samples was enrolled by a multistage sampling technique was used to recruit participants from five provinces in the lower northern of Thailand. Data were collected using a questionnaire and analyzed with descriptive statistics, and binary logistic regression. The results were revealed the risk factors affecting CKD including aged, dyslipidemia, being ill of diabetes mellitus, being unable to control blood pressure, being unable to control blood sugar level, taking add more salty seasoning to the cooked food, cooking with sodium salt over the prescribed amount, using the non-steroidal anti-inflammatory drug, lack of exercise, herbal plants consumption as drugs that are toxic to the kidney, edema, foamy urine, and nocturia. All risk factors were able to co-predict the risk to CKD about $83.2 \%$ at the 0.05 level of significance. Therefore, to prevent early states with CKD in the high-risk populations, the focus should be on encouraging health literacy because health literary it has a positive relationship with health-promoting behaviors. The health care provider needs to concentrate on increasing health literacy for self- management with them.
\end{abstract}

Keywords: Chronic kidney disease, high-risk population, Thailand

\section{INTRODUCTION}

Chronic kidney disease (CKD) is a serious health problem that has increased dramatically worldwide. CKD is a condition that has a strong relation to substantial morbidity, mortality, and economic loss. Approximately $13.4 \%$ of people globally are living with $\mathrm{CKD}^{1},{ }^{2}$. In Thailand, 8.4 million patients with CKD or $17.6 \%$ have been documented. Five levels of severity with estimated glomerular filtration rate, ranging from $1-5$ were recorded as $3.3 \%, 5.6 \%, 7.5 \%, 0.8 \%$ and $0.3 \%$ of prevalence respectively. It was found that $79.3 \%$ of patients were in the early stages (1-3) of CKD, while $20.7 \%$ of patients lived with late CKD stages (4-5) ${ }^{3,4}$. The cost for treatment of CKD is relatively high, especially for patients who have renal replacement therapy ${ }^{5,6}$. Consequently, the patients become pale, tired, weak, and could be infected easily, which could result in early death ${ }^{7}$. Concerning the quality of life, had a low quality of life and low self-esteem. They could not work as usual, which could affect their socio-economic status and negative societal impact. Moreover, it could have direct impacts on the caretakers due to time and income loss 8 .

Chronic kidney disease has gradually increased in the high-risk population of diabetic and hypertensive patients, resulting in high morbidity as well as mortality. The CKD causes complications in diabetic and hypertensive patients ${ }^{9}{ }^{10}$. The Thailand kidney foundation also stages of CKD were unknown by $98 \%$ of the risk population ${ }^{7}$. Nevertheless, a high prevalence of stage-3 CKD could occur among five provinces i.e. Phetchabun, Phitsanulok, Sukhothai, Tak, and Uttaradit provinces in the lower northern part of Thailand ${ }^{11}$. Interestingly, those high-risk populations are unaware of the risk factors are and whether those factors can be or cannot be related to CKD.

Former research revealed that many risk factors influencing the CKD were likely to increase which may have different contexts from other regions ${ }^{12}$, 13. Examining the risk factors for a certain population of certain geographical settings could help to deal with the progression of CKD. Even though the risk factors in each region are varied. As mentioned above, we attempted to investigate the risk factors influencing CKD in the high-risk population living in five provinces of the lower northern region of Thailand. Therefore, the study aims to determine factors influencing chronic kidney disease among the high-risk population.

\section{METHODS}

A cross-sectional study was conducted between November 2018 to April 2019. Sample and setting: The population consisted of two main groups of people with diabetes mellitus and/or hypertension who were living in five major provinces located in the lower northern, Thailand for more than six months and 
were chosen in this study. The sample size was calculated with the formula to estimate the finite population proportion ${ }^{14}$. The sample was enrolled by multistage sampling including stratified sampling, simple random sampling, and systematic sampling.

Inclusion criteria were as follows: 1) for cases: the high-risk groups who were diagnosed with CKD; 2) for controls: the high-risk groups who were diagnosed without CKD 3) samples who were willing to participate and 4) participants who were able to communicate in basic Thai language.

Exclusion criteria were as follows: 1) informants were sick during the interview; 2) informants left the research before completion and 3 ) all data from the interview was incomplete.

Ethical Considerations: Approval to conduct the study was gained from the Ethics Review Committee for Research Involving Human Research Subjects, by the human ethics committees of Naresuan University (No. 113/2018). Verbal consent was obtained from each potential participant prior to data collection. Each participant was informed regarding the purpose of study, and their rights to confidentiality and anonymity, as well as being able to terminate their study participation at any time with no effect on their hospital services.

Instruments: The questionnaire for data collection comprised a socio-demographic data form, risk behaviors and anxious behavior concerning sign and symptom. The questionnaire template consisted of questions concerning personal data and a personal factors-related character including the number of CKD i.e. age, gender, income, body mass index (BMI), waist circumference, duration of being diabetic, duration of being ill with high blood pressure, controlling blood sugar level, controlling the blood pressure level, gout, cardiovascular disease, anemia, kidney stone, dyslipidemia, benign prostatic hyperplasia, systemic lupus erythematosus and family history of kidney disease.

The risk behavior questionnaire followed the main work of Allen and Seaman ${ }^{15}$ with slight modification. Three rating scales i.e. regularly (practicing every day or more than three times a week), sometimes (practicing less than or equal to 1-2 times a week) and hardly ever (never practice) were designed. Regarding the number of CKD, the risk factors affecting for CKD i.e. cooking with sodium salt over the prescribed amount, using NSAIDs, herbal plants consumption that are toxic to the kidney, insufficient sleep, urinary incontinence, drinking less water, smoking, drinking alcohol, exercise and regular treatment are factors that could lead to chronic kidney disease in the high-risk population were also assigned. Additionally, for questionnaire involving the signs and symptoms, it was developed based on a literature review. Two major choices such as yes or no. i.e. edema (swollen of eyelids, face, feet or ankles), dysuria, turbid urine contains sand-like impurities, hematuria, foamy urine/proteinuria, and nocturia were included in this questionnaire form. Examining the quality of instrument: Item Objective Congruence Index was verified by five experts in the field of CKD in each item had IOC value between 0.5 and 1 . A questionnaire had reliability value of 0.85 .

Data collection: All respondents were interviewed and gathered by research assistants (RAs) who were trained for data collection from November 2018- April 2019. The procedures for human rights protection should be considered. The medical record review on each identified participant to collect personal data and other risk factors was conducted by RAs and those data obtained were reconfirmed by the principal investigator (PI).

Data analysis: Data were analyzed using descriptive statistics including percentage, frequency, mean, standard deviation, and minimum and maximum value. These statistics were used to explain the socio-demographic characteristics of the sample. Testing the relationship between the factors and CKD with the Chi-square test in the first step, testing the risk factors influencing CKD was performed using binary logistic regression analysis with the enter method. And tested to ensure the validity of the results with the stepwise method at the 0.05 level of significance.

\section{RESULTS}

\section{Baseline characteristics}

742 out of 1,463 participants were diagnosed as a patient with CKD (50.7\%). Meanwhile, a total of 721 respondents were registered as the high-risk populations without CKD (49.3\%) who have characteristics. The Socio-demographic characteristics showed that $66.5 \%$ were females. Most of them (77.4\%) completed primary schooling, $57.3 \%$ aged 60 years and above with the mean of $63.3 \pm 12.2$ years, and $50.7 \%$ were the risk population with CKD. The majority of them (64.0\%) had income less than 5,000 THB. Almost half of them are being agriculturists (42.7\%) (Table 1). 
Table 1 General characteristics of respondents $(n=1,463)$

\begin{tabular}{|c|c|c|c|}
\hline Characteristics & Totals (\%) & CKD (\%) & Non-CKD (\%) \\
\hline \multicolumn{4}{|l|}{ Gender } \\
\hline Male & $490(33.5)$ & $270(36.4)$ & $220(30.5)$ \\
\hline Female & $973(66.5)$ & $472(63.6)$ & $501(69.5)$ \\
\hline \multicolumn{4}{|l|}{ Age (years) } \\
\hline$<40$ & $39(2.7)$ & $4(0.5)$ & $35(4.9)$ \\
\hline $40-59$ & $585(40.0)$ & $175(23.6)$ & $410(56.9)$ \\
\hline$\geq 60$ & $839(57.3)$ & $563(75.9)$ & $276(38.2)$ \\
\hline \multicolumn{4}{|l|}{ Education } \\
\hline No study & $122(8.3)$ & $75(10.1)$ & $47(6.5)$ \\
\hline Elementary & $1132(77.4)$ & $625(84.2)$ & $507(70.3)$ \\
\hline High School & 209 (14.3) & $42(5.7)$ & $167(23.2)$ \\
\hline \multicolumn{4}{|l|}{ Main Job } \\
\hline No occupation & 555 (37.9) & $391(52.7)$ & $164(22.7)$ \\
\hline Agriculturist & $624(42.7)$ & $249(33.6)$ & $375(52.0)$ \\
\hline Employed & $162(11.1)$ & $48(6.5)$ & $114(15.8)$ \\
\hline Official & $122(8.3)$ & $54(7.2)$ & $68(9.5)$ \\
\hline \multicolumn{4}{|c|}{ Income per month } \\
\hline$<5,000(\mathrm{THB})$ & $937(64.1)$ & $540(72.8)$ & $397(55.0)$ \\
\hline$>5,000(\mathrm{THB})$ & $526(35.9)$ & $202(27.2)$ & $324(45.0)$ \\
\hline
\end{tabular}

The independent variables of personal factors including gender, age, income, waist circumference, diabetes mellitus, being ill of DM, being control DM, hypertensive, being ill of $\mathrm{HT}$, being control HT, dyslipidemia, and kidney stone. Risk behaviors such as flavoring food with salt, flavoring food with diverse seasonings over
2,000 milligrams, NSAIDs Consumption, exercise, herbal consumption, smoking, anxious behaviors regarding signs and symptoms, for example, edema, anemia, dysuria, urine turbidity, hematuria, foamy urine, and nocturia. The details of these factors associated with CKD can be seen in table 2 .

Table 2 Relationship between the risk factors and CKD with chi-square test $(n=1,463)$

\begin{tabular}{|c|c|c|c|c|c|c|}
\hline Variable & Total & Non-CKD & CKD & $\chi^{2}$ & df & p-value \\
\hline Gender & & & & 5.7 & 1 & $0.017^{*}$ \\
\hline Male & $490(33.5)$ & $220(30.5)$ & $270(36.4)$ & & & \\
\hline Female & $973(66.5)$ & $501(69.5)$ & 472 (63.6) & & & \\
\hline Age (years) & & & & 319.2 & 5 & $<0.001^{*}$ \\
\hline$<40$ & $39(2.7)$ & $35(4.8)$ & $4(0.5)$ & & & \\
\hline $40-59$ & $585(40.0)$ & $410(56.9)$ & $175(23.6)$ & & & \\
\hline$\geq 60$ & $839(57.3)$ & $276(38.3)$ & 563 (75.9) & & & \\
\hline Income per month & & & & 60.1 & 2 & $<0.001^{*}$ \\
\hline$<5,000(\mathrm{THB})$ & $937(64.1)$ & $397(55.1)$ & $540(72.8)$ & & & \\
\hline$\geq 5,000$ (THB) & $526(35.9)$ & $324(45.0)$ & $202(27.2)$ & & & \\
\hline BMI & & & & 6.5 & 1 & 0.011 \\
\hline$<25 \mathrm{~kg} / \mathrm{m}^{2}$ & $840(57.4)$ & $438(60.7)$ & $402(54.2)$ & & & \\
\hline$\geq 25 \mathrm{~kg} / \mathrm{m}^{2}$ & $623(42.6)$ & $283(39.3)$ & $340(45.8)$ & & & \\
\hline Waist circumference (cm) & & & & 21.2 & 1 & $<0.001^{*}$ \\
\hline Male $<90$ Female $<80$ & $680(46.5)$ & $379(52.6)$ & $301(40.6)$ & & & \\
\hline Male $\geq 90$ Female $\geq 80$ & $783(53.5)$ & $342(47.4)$ & 441 (59.4) & & & \\
\hline Diabetes Mellitus (DM) & & & & 31.3 & 1 & $<0.001^{*}$ \\
\hline No & $799(54.6)$ & $447(62.0)$ & $352(47.4)$ & & & \\
\hline Yes & $664(45.4)$ & $274(38.0)$ & $390(52.6)$ & & & \\
\hline Being ill of DM & & & & 126.6 & 2 & $<0.001^{*}$ \\
\hline$<5$ years & $1,032(70.5)$ & $603(83.6)$ & $429(57.8)$ & & & \\
\hline $5-10$ years & $216(14.8)$ & $75(10.4)$ & $141(19.0)$ & & & \\
\hline$>10$ years & $215(14.7)$ & $43(6.0)$ & $172(23.2)$ & & & \\
\hline Being control DM & & & & 107.0 & 1 & $<0.001^{*}$ \\
\hline Control $\mathrm{HbA} 1 \mathrm{C} \leq 7 \%$ & $959(65.6)$ & $572(79.3)$ & $387(52.2)$ & & & \\
\hline Uncontrolled $\mathrm{HbA} 1 \mathrm{C}>7$ \% & $504(34.4)$ & $149(20.7)$ & $355(47.8)$ & & & \\
\hline Hypertensive (HT) & & & & 14.2 & 1 & $<0.001^{*}$ \\
\hline No & $172(11.8)$ & $108(15.0)$ & $64(8.6)$ & & & \\
\hline Yes & $1291(88.2)$ & $613(85.0)$ & $678(91.4)$ & & & \\
\hline
\end{tabular}


Table 2 Cont.

\begin{tabular}{|c|c|c|c|c|c|c|}
\hline Variable & Total & Non-CKD & CKD & $\chi^{2}$ & df & p-value \\
\hline Being ill of $\mathrm{HT}$ & & & & 102.7 & 2 & $<0.001^{*}$ \\
\hline$<5$ years & $625(42.7)$ & $394(54.7)$ & $231(31.1)$ & & & \\
\hline $5-10$ years & $511(34.9)$ & $231(32.0)$ & $280(37.8)$ & & & \\
\hline$>10$ years & $327(22.4)$ & $96(13.3)$ & $231(31.1)$ & & & \\
\hline Being control HT (mmHg.) & & & & 276.1 & 1 & $<0.001^{*}$ \\
\hline Control BP $<140 / 90$ & $776(53.0)$ & $541(75.0)$ & $235(31.7)$ & & & \\
\hline Uncontrolled $B P \geq 140 / 90$ & $687(47.0)$ & $180(25.0)$ & 507 (68.3) & & & \\
\hline Gout & & & & 14.0 & 1 & $<0.001^{*}$ \\
\hline No & $1,295(88.5)$ & $661(91.7)$ & $634(85.4)$ & & & \\
\hline Yes & 168 (11.5) & $60(8.3)$ & $108(14.6)$ & & & \\
\hline Cardiovascular disease & & & & 20.8 & 1 & $<0.001^{*}$ \\
\hline No & $1,351(92.3)$ & $689(95.6)$ & $662(89.2)$ & & & \\
\hline Yes & $112(7.7)$ & $32(4.4)$ & $80(10.8)$ & & & \\
\hline Kidney stone & & & & 21.8 & 1 & $<0.001^{*}$ \\
\hline No & $1,365(93.3)$ & $695(96.4)$ & $670(90.3)$ & & & \\
\hline Yes & $98(6.7)$ & $26(3.6)$ & $72(9.7)$ & & & \\
\hline Dyslipidemia & & & & 180.7 & 1 & $<0.001^{*}$ \\
\hline No & $646(44.2)$ & $446(61.9)$ & $200(27.0)$ & & & \\
\hline Yes & $817(55.8)$ & $275(38.1)$ & $542(73.0)$ & & & \\
\hline $\begin{array}{l}\text { Benign prostatic hyperplasia, } \\
\text { No }\end{array}$ & $1,421(97.1)$ & 719 (99.7) & $702(94.6)$ & 34.3 & 1 & $<0.001^{*}$ \\
\hline Yes & $42(2.9)$ & $2(0.3)$ & $40(5.4)$ & & & \\
\hline Systemic lupus erythematosus & & & & 6.2 & 1 & $0.013^{*}$ \\
\hline No & $1,453(99.3)$ & 720 (99.9) & $733(97.6)$ & & & \\
\hline Yes & $10(0.7)$ & $1(0.1)$ & $18(2.4)$ & & & \\
\hline Family history of kidney disease & & & & 57.5 & 1 & $<0.001^{*}$ \\
\hline No & $1,195(81.7)$ & 645 (89.5) & $550(74.1)$ & & & \\
\hline Yes & $268(18.3)$ & $76(10.5)$ & $192(25.9)$ & & & \\
\hline $\begin{array}{l}\text { Taking add more salty seasoning } \\
\text { to the cooked food }\end{array}$ & & & & 208.2 & 2 & $<0.001^{*}$ \\
\hline Hardly ever & $446(30.5)$ & $340(47.2)$ & $106(14.3)$ & & & \\
\hline Sometimes & $757(51.7)$ & $316(43.8)$ & $441(59.4)$ & & & \\
\hline Regularly & $260(17.8)$ & $65(9.0)$ & $195(26.3)$ & & & \\
\hline Cooking with sodium salt over & & & & 82.3 & 2 & $<0.001^{*}$ \\
\hline Hardly ever & $129(8.8)$ & $84(11.6)$ & $45(6.1)$ & & & \\
\hline Sometimes & $818(55.9)$ & $464(64.4)$ & $354(47.7)$ & & & \\
\hline Regularly & $516(35.3)$ & $173(24.0)$ & $343(46.2)$ & & & \\
\hline NSAIDs use & & & & 257.1 & 2 & $<0.001^{*}$ \\
\hline Hardly ever & $534(36.5)$ & $396(54.9)$ & $138(18.6)$ & & & \\
\hline Sometimes & 724 (49.5) & $308(42.7)$ & $416(56.1)$ & & & \\
\hline Regularly & $205(14.0)$ & $17(2.4)$ & $188(25.3)$ & & & \\
\hline Exercise & & & & 205.2 & 2 & $<0.001^{*}$ \\
\hline Regularly & $236(16.1)$ & $173(24.0)$ & $474(63.9)$ & & & \\
\hline Sometimes & $557(38.1)$ & $352(48.8)$ & $205(27.6)$ & & & \\
\hline Hardly ever & $670(45.8)$ & $196(27.2)$ & $63(8.5)$ & & & \\
\hline Herbal plant consumption & & & & 111.2 & 2 & $<0.001^{*}$ \\
\hline No & $1,116(76.3)$ & $635(88.1)$ & $481(64.8)$ & & & \\
\hline Yes & $347(23.7)$ & $86(11.9)$ & $261(35.2)$ & & & \\
\hline Smoking & & & & 44.7 & 2 & $<0.001^{*}$ \\
\hline Non smoker & $982(67.1)$ & $544(75.5)$ & $438(59.1)$ & & & \\
\hline Smoker & $481(32.9)$ & 177 (24.5) & $304(40.9)$ & & & \\
\hline Edema & & & & 175.6 & 2 & $<0.001^{*}$ \\
\hline No & $1,201(82.1)$ & $689(95.6)$ & $512(69.0)$ & & & \\
\hline Yes & $262(17.9)$ & $32(4.4)$ & $230(31.0)$ & & & \\
\hline Anemia & & & & 63.5 & 2 & $<0.001^{*}$ \\
\hline No & $1,369(93.6)$ & $712(98.8)$ & $657(88.5)$ & & & \\
\hline Yes & $94(6.4)$ & $9(1.2)$ & 85 (11.5) & & & \\
\hline Dysuria & & & & 44.1 & 2 & $<0.001^{*}$ \\
\hline No & $1,222(83.5)$ & $649(90.0)$ & $573(77.2)$ & & & \\
\hline Var & 21111451 & 77 in ni & 14017281 & & & \\
\hline
\end{tabular}


Table 2 Cont.

\begin{tabular}{lrrrrrr}
\hline Variable & Total & Non-CKD & CKD & $\chi^{2}$ & df & p-value \\
\hline Urine Turbidity & & & & 61.1 & 2 & $<0.001^{*}$ \\
$\quad$ No & $1,315(89.9)$ & $693(96.1)$ & $622(83.8)$ & & & \\
$\quad$ Yes & $148(10.1)$ & $28(3.9)$ & $120(16.2)$ & & & \\
Hematuria & & & & 76.0 & 2 & $<0.001^{*}$ \\
$\quad$ No & $1,300(88.9)$ & $693(96.1)$ & $607(81.8)$ & & & \\
$\quad$ Yes & $163(11.1)$ & $28(3.9)$ & $135(18.2)$ & & & \\
Foamy urine & & & & 327.5 & 2 & $<0.001^{*}$ \\
$\quad$ No & $1,039(71.0)$ & $669(92.8)$ & $370(49.9)$ & & & \\
$\quad$ Yes & $424(29.0)$ & $52(7.2)$ & $372(50.1)$ & & \\
Nocturia & & & & 243.6 & 2 & $<0.001^{*}$ \\
$\quad$ No & $802(54.8)$ & $542(75.2)$ & $260(35.0)$ & & & \\
Yes & $661(45.2)$ & $179(24.8)$ & $482(65.0)$ & & & \\
\hline
\end{tabular}

* P-value $<0.05$

\section{Factors affecting CKD}

The result showed that the thirteen risk factors of CKD were divided into four groups as follows;

1) socio-demographic data including aged between $40-59$ years $(\mathrm{AOR}=3.84,95 \% \mathrm{Cl}=1.03$ 14.29, $\mathrm{P}$-value $=0.045), 60$ years and above, $(\mathrm{AOR}=12.07,95 \% \mathrm{Cl}=3.25-44.83, \mathrm{P}$-value $<0.001)$

2) history of the illness as dyslipidemia $(A O R=$ $1.56,95 \% \mathrm{Cl}=1.14-2.13$, $\mathrm{P}$-value $=0.006)$, being ill of DM between $5-10$ years $(A O R=2.20,95 \% \mathrm{Cl}$ $=1.35-3.59$, P-value $=0.002$ ), illness above 10 years $(\mathrm{AOR}=2.48,95 \% \mathrm{Cl}=1.42-4.31, \mathrm{P}$-value $=$ $0.001)$, uncontrolled blood sugar level $(A O R=$ $1.59,95 \% \mathrm{Cl}=1.05-2.41, \mathrm{P}$-value $=0.030)$, and uncontrolled blood pressure $(\mathrm{AOR}=3.20,95 \% \mathrm{Cl}=$ 2.34-4.38, P-value $<0.001$

3) health behavior such as taking add more salty seasoning $(A O R=3.15,95 \% \mathrm{Cl}=1.87-5.32, \mathrm{P}$ value $<0.001)$, flavoring food with diverse seasonings $(\mathrm{Na}+)$ over $(A O R=2.87,95 \% \mathrm{Cl}=1.66$ 4.98, P-value $<0.001$ ), using NSAIDs as regularly $(\mathrm{AOR}=3.49,95 \% \mathrm{Cl}=1.78-6.82, \mathrm{P}$-value $<0.001)$ moreover, lacking of exercise $(\mathrm{AOR}=3.46,95 \% \mathrm{Cl}$ = 2.19-5.45, P-value <0.001), applying herbal plants as drugs that are toxic to kidney $(A O R=$ $1.73,95 \% \mathrm{Cl}=1.24-2.40$, $\mathrm{P}$-value $=0.001)$, and

4) sign and symptoms as edema $(\mathrm{AOR}=2.51$, $95 \% \mathrm{Cl}=1.62-3.89, \mathrm{P}$-value $<0.001)$, foamy urine $(A O R=3.01, \quad 95 \% \mathrm{Cl}=1.98-4.58, \quad \mathrm{P}$-value $<0.001)$ and nocturia $(A O R=1.62,95 \% \mathrm{Cl}=1.18$ 2.24, $\mathrm{P}$-value $=0.003$ ) at the 0.05 significant level as demonstrated in Table 3. All risk factors were able to co-predict to CKD about $83.2 \%$ at the 0.05 level of significance.

\section{DISCUSSION}

The results showed the thirteen independent significant risk factors of CKD among the highrisk population in the lower northern, Thailand as follows:

Age is a risk factor ${ }^{16,17}$ reported that people aged more than 40 years old had a higher risk of CKD than people who were younger than 40 years old by 1.80 times $^{16}$.

Participants with dyslipidemia proposed that people who had high LDL- and low HDLcholesterol could be at high risk for $\mathrm{CKD}^{18}$ because dyslipidemia could cause atherosclerosis thereby delaying the stimulation of the kidney's function. This case was also conformed to Xue, et al $(2014)^{19}$ who claimed that the risk was about 1.30 times.

Duration of diabetic mellitus (DM), patients with DM over a prolonged period could cause inflammation of the blood vessels resulting in retarding the blood flow to the kidneys, ultimately leading to renal disease $e^{10,20}$.

Uncontrolled blood sugar level (HbA1c $>7 \%$ ) was related to the CKD (1.59 times). Abnormal blood sugar levels could make the blood to be more viscous, hampering its smooth flow to the kidneys, resulting in kidney failure ${ }^{17,21}$. Uncontrolled blood pressure was potential to increase about 3.20 times due to the high blood pressure that could bump up until the blood vessels narrow, resulting in insufficient blood flow to the kidney ${ }^{19}, 22$.

Add more salty seasoning to the cooked food, for instance, fish sauce with chili and sauce showed the health behavior salt intake, and many people unknown and aware. In addition, and cooking with sodium salt over the prescribed amount related to the $C K D^{23}, 24$. could easily cause water retention, resulting in renal disease. Koh, et al. $(2011)^{25}$ reviewed that reducing $\mathrm{Na}+$ concentration by about $20 \mathrm{mmol}$ a day could 
Table 3 Multivariate analysis between risk factors affecting the Chronic Kidney Disease $(n=1,463)$

\begin{tabular}{|c|c|c|c|}
\hline Variable & AOR & $95 \% \mathrm{Cl}$ & P- value \\
\hline \multicolumn{4}{|l|}{ Age } \\
\hline$<40$ years & 1.00 & & \\
\hline $40-59$ & 3.84 & $1.03-14.29$ & $0.045^{*}$ \\
\hline$\geq 60$ & 12.07 & $3.25-44.83$ & $<0.001^{*}$ \\
\hline Dyslipidemia (yes=1, no=0) & 1.56 & 1.14-2.13 & $0.006^{*}$ \\
\hline \multicolumn{4}{|l|}{ Duration of $\mathrm{DM})<5$ years $=0($} \\
\hline $5-10$ & 2.20 & $1.35-3.59$ & $0.002^{*}$ \\
\hline$>10$ & 2.48 & $1.42-4.31$ & $0.001^{*}$ \\
\hline Blood pressure) uncontrolled $=1$, control $=0$ ( & 3.20 & $2.34-4.38$ & $<0.001^{*}$ \\
\hline \multicolumn{4}{|l|}{ taking add more salty seasoning } \\
\hline Hardly ever & 1.00 & & \\
\hline Sometimes & 1.50 & $1.03-2.19$ & $0.034^{*}$ \\
\hline Regularly & 3.15 & $1.87-5.32$ & $<0.001^{*}$ \\
\hline \multicolumn{4}{|l|}{$\begin{array}{l}\text { cooking with sodium salt over the prescribed } \\
\text { amount }\end{array}$} \\
\hline Hardly ever & 1.00 & & \\
\hline Sometimes & 2.08 & $1.25-3.46$ & $0.005^{*}$ \\
\hline Regularly & 2.87 & $1.66-4.98$ & $<0.001^{*}$ \\
\hline \multicolumn{4}{|l|}{ NSAIDs Use } \\
\hline Hardly ever & 1.00 & & \\
\hline Sometimes & 1.41 & $1.00-2.00$ & $0.048^{*}$ \\
\hline Regularly & 3.49 & $1.78-6.82$ & $<0.001^{*}$ \\
\hline \multicolumn{4}{|l|}{ Exercise } \\
\hline Regularly & 1.00 & & \\
\hline Sometimes & 1.59 & $1.01-2.50$ & $0.046^{*}$ \\
\hline Hardly ever & 3.46 & $2.19-5.45$ & $<0.001^{*}$ \\
\hline Herbal consumption( yes $=1$, no $=0$ ) & 1.73 & $1.24-2.40$ & $0.001^{*}$ \\
\hline Edema $($ yes $=1$, no=0 $)$ & 2.51 & $1.62-3.89$ & $<0.001^{*}$ \\
\hline Foamy urine/proteinuria (yes $=1$, no=0) & 3.01 & $1.98-4.58$ & $<0.001^{*}$ \\
\hline Nocturia (yes $=1$, no $=0$ ) & 1.62 & $1.18-2.24$ & $0.003^{*}$ \\
\hline
\end{tabular}

* P-value $<0.05$

Regular use of non-steroidal anti-inflammatory drugs (NSAIDs) was associated with CKD.

postulated that taking NSAIDs had a higher risk for CKD around 1.2 times $^{3}$. Using NSAIDs for a long period could cause accumulation in the

kidney due to excretion and synthesis of prostaglandins is halted, resulting in $\mathrm{Na}+$ congestion $^{26}$.

Lack of exercise was a risk factor for CKD. People who have sometimes or never exercised had increased risks of CKD around 1.59 and 3.46 times when compared with people who have exercised regularly. Regular exercise could assist the circulatory system to increase blood flow, reinforcing the kidneys. Previous research reported that the glomerular filtration rate after exercise was 3 times of usual rate ${ }^{27}$.

Herbal plant consumption that is relatively toxic to kidneys could be a risk for CKD. The patients with DM or hypertension, who use herbals by boiling and drinking such as East Indian crew tree (Helicteres isora), Bitterleaf tree (Gymnanthemum extensum), Blue trumpet (Thunbergia laurifolia), Great morinda (Morinda citrifolia), River spiderwort (Tradescouldtia fluminensis), Cat's whiskers (Orthosiphon aristatus) and use of bolus. The medicines to reduce blood sugar or blood pressure are usually done for a long period effecting kidney failure ${ }^{4}$, 28 .

However, the sign and symptoms such as edema $^{29}$, the urinary foam/proteinuria ${ }^{30}$, and nocturia $^{31}$ related to the CKD. these signs and symptoms caused by kidney failure. Similarly, this could cause the water to be expelled from the body and more often than usual. It had been recorded that age could be a risk factor of about 1 time. Meanwhile, the CKD stage could be a risk factor of about 1.5 times. Besides, about $64.0 \%$ of clinical significance in patients with CKD was also explored ${ }^{31}$. 
The researchers have some limitations. Our design was a cross-sectional study and conducted the data with only the five provinces in the lower northern, Thailand.

In order, to prevent early states with CKD in patients with type 2 diabetes and hypertension, the focus should be on encouraging health literacy because health literary has a positive relationship with health-promoting behaviors. The health care provider needs to concentrate on increasing health literacy for selfmanagement with them.

In further research, develop health literacy for prevention the risk of CKD among the high-risk population.

\section{CONCLUSION}

In conclusion, the thirteen risk factors affecting the CKD among the high-risk population divide into four groups including 1) socio-demographic consists of age, 2) history of the illness such as dyslipidemia, duration of diabetes mellitus, uncontrolled blood sugar, and blood pressure, 3) health behavior as follows adding salty condiments on the cooked, cooking with sodium salt over, using the non-steroidal antiinflammatory drug, lack of exercise, herbal plants consumption, and 4) sign and symptoms such as edema, urinary foam/proteinuria, and nocturia.

\section{ACKNOWLEDGEMENTS}

This study would not have been possible without the support of many people. We would like to extend our sincere gratitude and appreciation for all of the hard work and dedication provided by the volunteers and staffs.

\section{REFERENCES}

1. Jha V, Garcia-Garcia G, Iseki K, et al. Chronic kidney disease: Global dimension and perspectives. The Lancet. 2013; 382(9888):260-72.

2. Hill NR, Fatoba ST, Oke JL, et al. Global Prevalence of Chronic Kidney Disease -A Systematic Review and Meta-Analysis.

PLoSOne. 2016; 11(7):1-18.

DOI: $10.1371 /$ journal.pone. 0158765 .

3. Ingsathit A, Thakkinstian A, Chaiprasert A, et al. Prevalence and risk factors of chronic kidney disease in the Thai adult population: Thai SEEK Study. NDT. 2009; 25(5):156775.

4. Health data center (Thailand). Service Plan for Chronic Kidney disease 2018. Available from (accessed 10 Jan 2019).

5. Honeycutt AA, Segel JE, Zhuo X, et al. Medical costs of CKD in the Medicare population. JASN. 2013; 24(9):1478-83.

6. National Health Security Office. National Health Security Fund Management Guide; Management of Chronic kidney disease services. Nonthaburi: sahamitr-printing-andpublishing. 2008-2013. (in Thai).

7. Ingsathit A, Chayakul C, Chaiprasert A, et al. (2017). Progression and outcomes of CKD in Thai SEEK population. Health Systems Research Institute. Available form https://kb.hsri.or.th/dspace/bitstre am/handle/11228/4768/hs2353.pdf?s equence $=3 \&$ is March 2018).

8. Kasemsup W, Limwattananonta $S$, Limwattananon C, et al. Evaluation of Access to services and renal replacement services under the health insurance system in Thailand. Available from http: / / kb.hsri.or.th/dspace/handle/ (accessed 10 Jan 2019).

9. CDC-INFO Contact Center. (2017). Take care of your kidneys and they will take care of you. Available form www.cdc.gov/ckd (accessed 19 March 2018).

10. Vejakama P, Ingsathit A, Attia J, et al. Epidemiological study of chronic kidney disease progression: a largescale population-based cohort study. Medicine. 2015; 94(4): 1-8.

11. Health data center (Thailand). Service Plan for Chronic Kidney disease 2019. Available from https: / /hdcservice.moph.go.th/hdc/ reports/(accessed 19 Jan 2019).

12. Bang H, Vupputuri S, Shoham DA, et al. Screening for occult renal disease (SCORED): a simple prediction model for chronic kidney disease. Arch Intern Med. 2007; 167(4): 374-81.

13. Thakkinstian A, Ingsathit A, Chaiprasert A, et al. A simplified clinical prediction score of chronic kidney disease: A cross-sectionalsurvey study. BMC nephrology. 2011; 12.1:45. 
14. Wayne WD. Biostatistics: A Foundation of Analysis in the Health Sciences (6th Ed.). John Wiley\&Sons, Inc. 1995.

15. Allen IE, and Seaman CA. Likert scales and data analyses. Quality progress. 2007; 40(7): 64

16. Soongkhang $S$, Wangkaew S. Factors influence to the treatment results of chronic kidney disease In Diabetic patients in Udon Thani province. The Office of DPC 7 Khon Kaen. 2018; 24(2):1-9. (In Thai).

17. Wongprakob N, Piyabunditkul L. Predictive Factors of Chronic Kidney Disease in Patients with Diabetes Mellitus and Hypertension. Baromarajonani College of Nusing, Nakhonratchasima. 2017; 23(2):94106. (in Thai)

18. Lanktree $M B$, Theriault $S$, Walsh $M$, et al. HDL cholesterol, LDL cholesterol, and triglycerides as risk factors for CKD: a Mendelian Randomization

Study. AJKD.2018; 71(2): 166-72.

19. Xue L, Lou Y, Feng X, et al. Prevalence of chronic kidney disease and associated factors among the Chinese population in Taian, China. BMC nephrology. 2014; 15(1):205.

20. Laksawud S. Factor affecting diabetes nephropathy of diabetes type 2 patient, Nongkungsri hospital, Kalasin public health office 2013. RDHS. 2013; 7(1):272-28. (in Thai).

21. Consortium of Thai Medical, (Nonthaburi). Risk Factors for Diabetic Nephropathy in Type 2 Diabetic Mellitus visiting Hospitals in care of Ministry of Public Health and Bangkok Metropolitan Administration in Thailand. 2016. (in Thai).

22. Kovesdy C, Lu J, Molnar M, et al. Observational modeling of strict vs conventional blood pressure control in patients with chronic kidney disease. JAMA internal medicine, 2014; 174.9:1442-49.

23. Bureau of Nutrition. Survey report of sodium chloride intake of Thai population, Available from:
www.sem100library.in.th/opac/Catal og/Bibltem (accessed 19 Jan 2019). (in Thai).

24. Ruaisungnoen W, Saensom D, Methakanjanasak $\mathrm{N}$, et al. High sodium consumption situation and perception relevant to high sodium consumption associated with chronic kidney disease among people with chronic non-communicable disease. JNHC. 2018; 36(3):242-50. (in Thai).

25. Koh KH, Tan C, Hii L. Study of low salt diet in hypertensive patients with chronic kidney disease (CKD). IJC. 2011; 152: S104.

26. Nderitu P. Non-steroidal antiinflammatory drugs and chronic kidney disease progression: a systematic review. Family Practice. 2013; 30(3):247-55.

27. Greenwood SA, Koufaki P, Mercer $\mathrm{TH}$, et al. Effect of exercise training on estimated GFR, vascular health, and cardiorespiratory fitness in patients with CKD:a pilot randomized controlled trial. AJKD. 2015; 65(3):425-34.

28. MY Lin, YW Chiu, $\mathrm{CH}$ Lee, et.al. Factors associated with CKD in the elderly and nonelderly population. CJASN. 2013; 8(1):33-40.

29. Kang KK, Choi JR, Song JY, et al. Clinical Significance of Subjective Foamy Urine. CMJ.2012; 48(3):16468.

30. Pisharam JK, Daiwajna R, Chong VH, et al. Correlation of Urinary Foam with Proteinuria in Patients with Chronic Kidney Disease. Transl Biomed. 2017; 8:2. DOI: $10.21767 / 2172-0479.100110$

31. Wu MY, Wu YL, Hsu YH, et al. Risks of Nocturia in Patients with Chronic Kidney Disease-Do the Metabolic Syndrome and its Components Matter. AUAJ. 2012; 188(6):2269-73. 